\title{
ARTIGOS
}

Recebido em 29.11.2012. Aprovado em 21.05.2013. Avaliado pelo sistema double blind review.

Editores Científicos: Luciano Prates Junqueira, Sylmara Lopes F. Gonçalves-Dias e Patrícia Mendonça

\section{CADEIA REVERSA DO ÓLEO DE COZINHA: COORDENAÇÃO, ESTRUTURA E ASPECTOS RELACIONAIS}

\author{
Reverse chain of cooking oil: coordinación, structure and relational aspects \\ Cadena inversa del aceite de cocina: coordenación, estructura y aspectos \\ relacionales
}

\begin{abstract}
RESUMO
As atividades de produção e consumo geram resíduos que, conforme o destino, produzem impactos negativos no meio ambiente. Essa situação agravou-se, de maneira crítica, a partir da Revolução Industrial. Para reaproveitar esses resíduos, são necessárias novas formas de produzir, consumir e dar um destino adequado aos produtos após o final de seu ciclo de vida útil. Com base nesse contexto, o objetivo deste estudo é analisar como se estrutura e é coordenada uma cadeia de suprimentos reversa, tendo como objeto a coleta de óleo de cozinha utilizado. 0 caminho metodológico observa a abordagem qualitativa e caracteriza-se como exploratório. Em termos teóricos, o estudo orienta-se pelas abordagens de cadeias de suprimentos reversas e coordenação da cadeia de suprimentos. Os resultados evidenciam a iniciativa de uma empresa que não trabalha com óleo de cozinha utilizado, mas utiliza uma estratégia a partir desse resíduo para desencadear o processo de estruturação da cadeia analisada. Como principal contribuição, o estudo sugere a consolidação da quinta fase da logística: a Reverse Supply Chain (RSC).
\end{abstract}

PALAVRAS-CHAVE | Cadeia de suprimentos reversa, óleo de cozinha utilizado, estrutura, coordenação, relações.

\begin{abstract}
Production and consumption activities generate residues that, according to their disposal, produce negative impacts on the environment. This situation worsened critically after the Industrial Revolution. In order to reuse these residues, new forms of producing, consuming and proper disposal for these products are needed after the end of their life cycle. Based on this context, the objective of this study is to analyze how a reverse supply chain of the collection of used cooking oil is structured and coordinated. The methodological path observes the qualitative approach and characterizes itself as exploratory. In theoretical terms, the study is guided by the reverse supply chain and the supply chain coordination approaches. Results show the initiative of a company that does not work with used cooking oil, but employs a strategy based on this residue for triggering the structuration process of the chain under analysis. As its main contribution, the study suggests the consolidation of the fifth stage of logistics: Reverse Supply Chain (RSC).
\end{abstract}

KEY WORDS | Reverse supply chain, used cooking oil, structure, coordination, relations.

\section{RESUMEN}

Las actividades de producción y consumo generan residuos que, según el destino, producen impactos negativos en el medio ambiente. Esta situación se agravó, de manera crítica, a partir de la Revolución Industrial. Para reaprovechar estos residuos, son necesarias nuevas formas de producir, consumir y dar un destino adecuado a los productos después del final de su ciclo de vida útil. Con base en este contexto, el objetivo de este estudio es analizar cómo se estructura y es coordinada una cadena de suministros inversa, teniendo como objeto la recolección de aceite de cocina usado. El camino metodológico cumple con el abordaje cualitativo y está caracterizado como exploratorio. En términos teóricos, el estudio se orienta por los abordajes de cadenas de suministros inversa en coordinación con la cadena de suministros. Los resultados ponen en evidencia la iniciativa de una empresa que no trabaja con aceite de cocina usado, pero utiliza una estrategia a partir de este residuo para desencadenar el proceso de estructuración de la cadena analizada. Como principal contribución, el estudio sugiere la consolidación de la quinta etapa de la logística: la Reverse Supply Chain (RSC).

PALABRAS CLAVE | Cadena de suministros inversa, aceite de cocina usado, estructura, coordinación,

\section{TANIA NUNES DA SILVA}

do Sul - Porto Alegre-RS, Brasil relaciones.. 


\section{INTRODUÇÃO}

O resíduo do óleo de cozinha proveniente das residências, comércio e indústria é um item potencialmente poluidor quando descartado de maneira inadequada, sendo necessárias alternativas que possibilitem a sua reciclagem, promovendo-se o equilíbrio entre os âmbitos ambiental, econômico e social.

De acordo com o Programa de Gestão Ambiental (PGA) (2012), do Ministério Público Federal, um litro de óleo de cozinha utilizado contamina um milhão de litros de água - o suficiente para uma pessoa usar durante 14 anos. Isso acontece porque o óleo impede a troca de oxigênio e mata seres vivos como plantas, peixes e microrganismos. Além disso, impermeabiliza o solo, contribuindo para as enchentes.

Experiências de reutilização de produtos ao final de seu ciclo de vida útil ou de cadeias reversas que coloquem esses produtos em novos ciclos produtivos ainda são incipientes. Pode-se elencar casos como o do Instituto Nacional de Processamento de Embalagens Vazias (INPEV), que define a responsabilidade de cada elo da cadeia de defensivos agrícolas, criado com base na Lei n. 9.974, de 2000; o caso da HP, que usa a logística reversa para coletar produtos e suprimentos de sua marca (HEWLET PACKARD DO BRASIL, 2013); o caso da Claro, que desenvolveu parceria com a GM\&C Logística para recolhimento e envio de baterias e celulares para a reciclagem na Umicore, situada na Bélgica (CAMELO, COELHO, BORGES, 2010). Cita-se, também, o McDonald's, que transforma em biodiesel o óleo de cozinha usado em frituras, utilizando-o em caminhões de entrega às lojas da empresa (CAETANO, 2010).

Há, ainda, outros casos de reaproveitamento de óleo de cozinha, por meio de iniciativas do poder público em parceria com ONGs e outras entidades. Nos municípios de Ribeirão Preto, Salvador, Florianópolis, Rio de Janeiro, Porto Alegre e Curitiba, esse produto é recolhido para ser transformado em resina de tintas, sabão, ração animal e biodiesel.

Contudo, tanto as iniciativas de reaproveitamento do óleo de cozinha quanto de outros produtos, ao final do seu ciclo de vida útil, ainda são esparsas e não contam com cadeias organizadas para recolocar esses produtos em ciclos produtivos em escala competitiva.

Nos últimos anos, entretanto, emerge a abordagem das cadeias de suprimentos reversas, que tratam dos fluxos reversos de bens e produtos após o final de seu ciclo de vida útil, isto é, como recolocar esses bens e produtos em ciclos produtivos. Em determinadas situações, a legislação obriga a indústria e outros atores da cadeia de suprimentos a dar um destino adequado aos produtos após o final de seu ciclo de vida útil, como é o caso das embalagens de agrotóxicos (WILKE, 2009) e o da
Lei n. 12.305, que institui a Política Nacional de Resíduos Sólidos (BRASIL, 2010).

Há, também, a emergência de estudos sobre o reaproveitamento de produtos ao final de seu ciclo de vida útil, como o de Kumar e Malegeant (2006), que relatam a iniciativa da Nike, em parceria com ONGs voltadas a questões ecológicas, para implementação de um programa de reaproveitamento de calçados usados; o de Jabour (2010), que aborda a inserção de preocupações ambientais na Função Produção em empresas brasileiras; o de Coelho, Castro e Gobbo Jr. (2011), que tratam da reciclagem de garrafas PET; o de Souza e outros (2012), em que é abordado o uso do óleo de cozinha utilizado para fritura como insumo na produção de biodiesel no distrito de Copacabana (RI); e o de Jabour e Jabour (2012), que tratam da gestão ambiental em empresas do setor eletroeletrônico no Brasil. Porém, estudos focados na estruturação e coordenação de cadeias de suprimentos reversas ainda são raros.

Assim, dadas a problemática gerada pelo descarte inadequado do óleo de cozinha utilizado e, em contrapartida, a possibilidade de reaproveitamento, se estabelece como questão central deste estudo: Como a estrutura e coordenação da cadeia de suprimentos reversa do óleo de cozinha utilizado pode contribuir para minimizar o seu impacto, no meio ambiente? Para a construção da resposta, coloca-se como objetivo analisar como se estrutura e é coordenada uma cadeia de suprimentos reversa de óleo de cozinha utilizado.

O caminho metodológico do estudo observa a abordagem qualitativa e, quanto aos procedimentos, caracteriza-se como exploratório. Na coleta de dados primários, realizaram-se seis entrevistas, sendo cinco com gestores das empresas participantes da cadeia analisada e uma com um colaborador de uma dessas empresas. As entrevistas ocorreram nos meses de dezembro de 2011 e janeiro de 2012. Os dados secundários foram extraídos de web pages das empresas analisadas e de estudos e publicações pertinentes. A análise dos dados seguiu a lógica interpretativo-analítica.

A teoria de base ao estudo aborda os temas de cadeias de suprimentos reversas, pontuando-se, especialmente, as razões pelas quais são estruturadas (TIBBEN-LEMBKE, 2002; REVLOG, 2012) e a coordenação da cadeia de suprimentos, em que se enfatizam as formas de relações entre os atores (HANDFIELD e BECHTEL, 2002).

No que tange à coordenação da cadeia de suprimentos, este estudo segue linhas de estudos como os de Furlanetto (2002); Cerra, Maia e Alves Filho (2007); Kanda e Deshmukh (2008); Cachon e KöK (2010). Sobre cadeias de suprimentos reversas, o estudo visa a se aproximar de e aprofundar os estudos de Krikke (1998); Guide Junior e Van Wassenhove (2002); Lacerda (2002); Guide Junior, Harrisson e Van Wassenhove (2003); 
Blackburn e outros (2004); Prahinski e Kocabasoglu (2006); Shultmann, Zunkeller e Rentz (2006); Srivastava (2007); La Fuente, Ros e Cardós (2008).

A estrutura deste estudo, após a introdução, observa o caminho metodológico, referencial teórico, resultados e as considerações finais.

\section{CAMINHO METODOLÓGICO}

No desenvolvimento do estudo, optou-se pela abordagem qualitativa, pois se buscou caracterizar como se estrutura e é coordenada uma cadeia de suprimentos reversa de óleo de cozinha utilizado.

Quanto aos procedimentos, o estudo caracteriza-se como exploratório e não conclusivo, servindo para uma melhor compreensão do campo pesquisado (MALHOTRA, 2006), uma vez que as abordagens sobre cadeias de suprimentos reversas se constituem em um campo teórico e prático ainda em consolidação.

No levantamento de dados primários, realizaram-se seis entrevistas, como demonstrado no Quadro 1.
A duração das entrevistas por telefone foi de, em média, 15 minutos cada uma, enquanto as entrevistas face a face foram de 25 minutos.

Foram utilizados, também, dados secundários obtidos de web pages das empresas analisadas, documentos dessas empresas, como jornais de circulação periódica, além de dados extraídos de outros estudos e publicações que abordassem o tema em pauta.

Na definição das empresas a serem pesquisadas, optouse pela Porto Gás, em virtude de anúncios que esta distribui, por meio de folders em caixas de correios, sobre a estratégia de recolhimento de óleo de cozinha utilizado, quando faz a entrega do gás de cozinha. Essa estratégia de marketing despertou interesse pelo caso. Entrou-se em contato com a Porto Gás e por ela foram indicadas as demais empresas.

$\mathrm{Na}$ análise dos dados, seguiu-se a lógica interpretativo-analítica (SEVERINO, 2002), em que se procurou interpretar significados expostos ou contidos nas entrelinhas das falas dos entrevistados e também dos conteúdos, sem interferências pessoais valorativas.

\section{Quadro 1. Caracterização dos entrevistados}

\begin{tabular}{l|l|l|l|l}
\hline & Empresa & Entrevistado & Tipo & Mês \\
\hline 1 & Liquigás Distribuidora de Gás S.A. & Gestor & Telefone e e-mail & Dezembro/2011 \\
\hline 2 & Porto Gás & Gestor & Face a face & Dezembro/2011 \\
\hline 3 & Porto Gás & Gestor & Face a face & Dezembro/2011 \\
\hline 4 & Porto Gás & Colaborador & Face a face & Janeiro/2012 \\
\hline 5 & Coleto Óleos Vegetais Saturados Ltda. & Gestor & Telefone & Janeiro/2012 \\
\hline 6 & $\begin{array}{l}\text { Grupo Faros - Indústria de Farinha de Ossos Ltda.e } \\
\text { Base Indústria e Comércio de Óleos e Proteínas Ltda. }\end{array}$ & Gestor & Telefone & Janeiro/2012 \\
\hline
\end{tabular}

\section{REFERENCIAL TEÓRICO}

O marco teórico que sustenta este estudo aborda cadeias de suprimentos reversas e a coordenação da cadeia de suprimentos. Essa delimitação teórica procura oferecer a base suficiente para concatenar e embasar a análise e discussão dos resultados.

\section{Cadeias de suprimentos reversas}

A abordagem de fluxos e canais reversos, conforme Gonçalves-Dias e Teodósio (2006), se evidencia na literatura desde os anos 1970, porém de maneira esporádica. 0 conceito de cadeia de suprimentos reversa ainda está em construção, com crescente interesse por parte de acadêmicos e gestores de empresas.
As empresas, cada vez mais, são compelidas a lidar com a devolução/retorno de seus produtos, obrigadas por regulamentações ambientais e pelos custos crescentes com o descarte de produtos (PRAHINSKI e KOCABASOGLU, 2006). Para o RevLog (2012), os motivos pelos quais as empresas desenvolvem e implementam estratégias de logística reversa (estruturando cadeias de suprimentos reversas) são diversos; entre os principais, elenca:

- leis ambientais que forçam as empresas a recolherem seus produtos e cuidar da manutenção e tratamento;

- benefícios econômicos de usar produtos devolvidos no processo de produção em vez de pagar pelos altos custos de eliminação; e

- a crescente consciência ambiental dos consumidores. 
Além destes motivos, Tibben-Lembke (2002) relaciona razões estratégicas:

- razões competitivas - diferenciação por serviço;

- limpeza dos canais de distribuição;

- proteção das margens de lucro; e

- recaptura de valor e recuperação de ativos.

No que diz respeito às crescentes restrições que os marcos regulatórios exercem sobre as atividades produtivas, pode-se exemplificar com a Diretiva n. 293/2005 da União Europeia, que estabelece metas $95 \%$ de reutilização e reciclagem de veículos após o final de sua vida útil, até 2015 (AGRAWAL, 2012). No Brasil, citam-se a Lei n. 9.974, de 2000, que estabelece as diretrizes sobre a gestão de embalagens de defensivos agrícolas, e a Lei n. 12.305, que institui a Política Nacional de Resíduos Sólidos (BRASIL, 2010).

Em relação à recaptura de valor, cada tipo de retorno demanda uma cadeia de suprimentos reversa, adequada às características dos produtos que retornam para otimizá-la (GUIDE JUNIOR, HARRISON, VAN WASSENHOVE, 2003). Além disso, “[...] devoluções de produtos e suas cadeias de suprimentos reversas representam uma oportunidade para criar um fluxo de valor” (BLACKBURN e outros, 2004, p. 2).

Para Bowersox, Closs e Helferich (1986, p. 16),

A Logística Reversa não serve necessariamente para aprimorar a produtividade logística. No entanto, o movimento reverso é justificado sobre uma base social e deve ser acomodado no planejamento do sistema logístico. [...] 0 ponto importante é que a estratégia logística não poderá ser formulada sem uma consideração cuidadosa dos requerimentos da logística reversa.

As cadeias de suprimentos reversas tornam possível o retorno de bens ou de materiais ao ciclo produtivo, agregando valor econômico, legal e ecológico (LEITE, 2003). Os objetivos principais dessa lógica são os de recapturar valor e oferecer uma disposição final adequada (NOVAES, 2007).

Os aspectos estruturantes das cadeias de suprimento reversas podem ser de natureza econômica, quando objetivam resultados financeiros e lucro; de serviço ao cliente, quando procuram oferecer diferenciais da empresa nos serviços prestados; institucionais, quando visam à observação dos marcos regulatórios pertinentes; de cidadania corporativa, quando o objetivo é de atender a demandas de stakeholders, e visam legitimar, reforçar ou proteger a imagem corporativa ou da marca (LEITE, 2006).

Entre os fatores que determinam a estruturação de cadeias de suprimentos reversas, não está somente o tipo de pro- duto, mas as opções de reutilização, remanufatura, reciclagem etc. 0 desenvolvimento desse sistema demanda uma análise detalhada das questões técnicas, ambientais, econômicas para viabilizá-lo (TERPEND e outros, 2008; RUBIO e outros, 2009).

A abordagem da cadeia de suprimentos reversa mantém relação sistêmica com a green supply chain management, fazendo parte desse moderno conceito de gestão da cadeia de suprimentos. Nesse sentido, alguns autores têm se dedicado ao estudo dos desafios das empresas brasileiras, no que diz respeito à internalização dos pressupostos dessa abordagem em seus processos produtivos e, também, ao longo de suas cadeias de suprimentos.

Destarte, destaca-se o estudo de Jabour (2010), o qual analisa a introdução das questões ambientais no contexto da função de produção, como a área organizacional adequada para liderar a gestão ambiental corporativa. Coelho, Castro e Gobbo Jr. (2011) tratam de qual seria, no Brasil, o melhor destino de garrafas PET, concluindo que o fim mais adequado é a produção de contêineres.

Jabour e Jabour (2012) verificam a relação entre a evolução da gestão ambiental e a adoção de práticas de green supply chain management por empresas do setor eletroeletrônico do Brasil, com destaque para os fatores determinantes dessas práticas: orientação a fornecedores, orientação a consumidores e orientação para a recuperação de investimentos. E, também, Souza e outros (2012), que abordam o uso do óleo de cozinha utilizado para fritura como insumo na produção de biodiesel no distrito de Copacabana (RJ), com ênfase em questões socioeconômicas.

\section{Coordenação da cadeia de suprimentos}

A literatura sobre a coordenação da cadeia de suprimentos tem analisado diferentes formas contratuais com base em um único fabricante e um ou mais distribuidores. Uma das conclusões mais relevantes dessa análise é que contratos (simples) que definam preços de vendas podem levar a decisões subótimas para a cadeia de abastecimento. Por outro lado, contratos sofisticados podem ser empregados para alcançar tanto a coordenação da cadeia de suprimentos (ou seja, maximizar o lucro da cadeia de suprimentos) quanto uma maior extração de renda (capacidade de alocar uma percentagem elevada dos lucros para o fabricante) (CACHON e KÖK, 2010).

A coordenação da cadeia de suprimentos pode, também, ser baseada na confiança. Esse tipo de coordenação pode implicar riscos, quando haveria comportamento oportunista de parte de algum dos atores da cadeia (WILLIAMSON, 1996). Porém, os custos com mecanismos de coordenação seriam reduzi- 
dos e até minimizados quando a coordenação fosse determinada por meio da confiança (HANDFIELD e BECHTEL, 2002).

0 papel da confiança nos parceiros em uma estrutura como a cadeia de suprimentos é um elemento bastante presente na literatura pertinente. Nesse sentido, existe o pressuposto de que a confiança contribui para o êxito de alianças (SILVA e outros, 2004). Para Barney e Hansen (1994), confiança é a mútua segurança de que nenhum dos atores agirá de maneira oportunista, explorando eventuais vulnerabilidades de seus parceiros.

As cadeias de suprimentos são estruturadas como se fossem uma grande empresa, onde as diferentes empresas que a compõem assumem a lógica de estágios ou operações desta. Para que ela se torne eficiente, é preciso que haja coordenação dos diferentes atores que interagem entre si - na cadeia - e tenha, também, interações com outras empresas fora da cadeia. A coordenação da cadeia de suprimentos abrange "[...] atividades e processos não apenas dentro de uma organização, mas entre todas as que compõem a cadeia de suprimentos, partindo do pressuposto de que há benefícios significativos a serem ganhos ao se dirigir estrategicamente a cadeia em direção à satisfação dos clientes finais" (CERRA, MAIA, ALVES FILHO, 2007, p. 2).

A coordenação da cadeia de suprimentos visa buscar o melhor desempenho em nível de cadeia, e não o ponto ótimo de modo individual para cada estágio. A coordenação contribui para que cada estágio da cadeia tome decisões que levem a lucros totais e evitem somente melhorias individuais ou isoladas (CHOPRA e MEINDL, 2010), pois nenhuma operação produtiva existe isoladamente (SLACK, CHAMBERS, JOHNSTON, 2007).

0 arranjo dos esforços entre funções em várias empresas que colaboram para atingir objetivos comuns é tido como o principal objetivo do gerenciamento da cadeia de suprimentos (RODRIGUES e SELLITTO, 2007). A cooperação entre as empresas participantes da cadeia de suprimentos faz-se necessária para que seja garantido o fornecimento do produto final (LAMMING, 1993), e as parcerias podem ser definidas como "[...] o compartilhamento de riscos e recompensas de tecnologia e inovação, levando à redução de custos, ao aprimoramento na entrega e na qualidade, e à ampliação de vantagem competitiva sustentada" (SLACK, CHAMBERS, JOHNSTON, 1997, p. 433). Essa lógica sustenta-se na perspectiva de que a entrada de um parceiro pode trazer redução de risco ou aumento de eficiência na cadeia (LARSON, POIST, HALLDORSSON, 2007).

Para que seja atingida a coordenação, cada estágio precisa levar em consideração os impactos que suas ações terão sobre os demais estágios. 0 principal desafio, nesse sentido, é que as cadeias tenham coordenação, apesar do grande nú- mero de atores envolvidos, da complexidade das relações e crescente diversificação de produtos e serviços (CHOPRA e MEINDL, 2010). Essa perspectiva evidencia a interdependência entre os atores da cadeia, quando comprometidos com o objetivo de satisfazer as necessidades do consumidor final (MARTINS e SOUZA, 2010). Assim, as estratégias individuais dos elos das cadeias de suprimento devem alinhar-se às estratégias competitivas de toda a cadeia (CHOPRA e MEINDL, 2003).

Lambert, Cooper e Pagh (1998) argumentam que a coordenação da cadeia de suprimentos pode ser determinada a partir de um de seus atores, que seria a empresa focal, pois esta teria maior poder em virtude de algum aspecto como: barganha nas transações, deter ativos raros, estar mais próxima do cliente, como é o caso de grandes varejistas. Para Talamini, Pedrozo e Silva (2005, p. 110), “A empresa focal é aquela a partir da qual a cadeia de suprimentos é analisada, tanto nas ligações desta com os fornecedores de matérias-primas, quanto com os demais membros posteriores a ela." Sellitto e Mendes (2006, p. 560) sustentam que "[...] a empresa focal tem autonomia para gerar restrições e formular estratégias para a cadeia de suprimentos".

Por meio da coordenação, são viabilizadas estratégias em nível de cadeia, pois os mecanismos de governança que estruturam a coordenação permitem que se alinhem as ações dos atores envolvidos. Assim, por exemplo, se, para entrar em determinado mercado, é necessária a certificação ambiental do produto ou serviço, poderá ser exigida certificação para todos os atores dessa cadeia.

\section{APRESENTAÇÃO DOS RESULTADOS, ANÁLISE E DISCUSSÃO}

O óleo de cozinha utilizado, caracterizado como o produto usado para fritura de alimentos, uma vez acondicionado e recolhido de maneira adequada, pode ter diversos fins. Entre as diferentes possibilidades de (re)utilização, Reis, Ellwanger e Fleck (2007) citam:

- produção de glicerina;

- padronização para composição de tintas;

- produção de massa de vidraceiro;

- produção de farinha básica para ração animal;

- geração de energia elétrica por meio de queima em caldeira; e

- produção de biodiesel, obtendo-se glicerina como subproduto. 
Apesar das possibilidades, o óleo de cozinha utilizado ainda é pouco usado. Não existem estatísticas oficiais quanto ao percentual de óleo de cozinha que volta aos ciclos produtivos. Para este trabalho, utiliza-se o estudo de Santos (2009, p. 30), que defende que “[...] no Brasil são descartados 9 bilhões de litros de óleo de cozinha por ano, mas apenas 2,5\% de todo esse óleo de fritura é reciclado". Se forem considerados esses dados ou, mesmo, estatísticas aproximadas, deduz-se que são reaproveitados de maneira adequada em torno de 225 milhões de litros de óleo de cozinha por ano. Por outro lado, os resíduos descartados de maneira inadequada no meio ambiente, a cada ano, apresentam potencial para poluir 8,775 trilhões de $\mathrm{m}^{3} \mathrm{de}$ água. Para se ter uma noção do quanto esse volume representa sobre a água tratada, a Sabesp, por ano, na região metropolitana de São Paulo, trata 3,311 bilhões de m³ (SABESP, 2012). Comparativamente, seriam necessários 2.650 anos para a Sabesp tratar a água poluída pelo descarte inadequado do óleo de cozinha, durante um ano, no Brasil.

Neste estudo, não se buscou analisar somente uma empresa isolada e como esta desenvolve estratégias de reaproveitamento do óleo de cozinha utilizado, mas verificar como se estrutura essa cadeia de suprimentos reversa e como ela é coordenada. Para melhor compreensão, caracteriza-se, de maneira discriminada, cada um dos atores envolvidos na cadeia estudada e o papel que ele desempenha.

\section{Liquigás Distribuidora de Gás - empresa focal}

A Liquigás é denominada, neste estudo, empresa focal, por ser a empresa que concebeu e desenvolveu a ideia do recolhimento de óleo de cozinha utilizado e sugeriu a seus revendedores essa ideia, sendo a adesão espontânea, sem sanções a quem não adote essa estratégia e, também, sem benefícios diretos por parte da distribuidora àquelas revendas que aderem à ideia.

Nesse sentido, a empresa mantém um jornal, que consta de sua web page, no qual são divulgadas experiências exitosas de suas revendas em todo o escopo de negócios, inclusive dessas estratégias de recolhimento de óleo de cozinha usado. Na sétima edição desse jornal, é relatado que, “[...] além da responsabilidade socioambiental, os revendedores acreditam que o desenvolvimento de ações desta natureza ajuda a consolidar a imagem do empreendimento, aproximando-o da comunidade" (JORNAL LIQUIGÁS, 2009, p. 7). Essa perspectiva leva a crer que uma explicação para a estratégia da Liquigás possa ser aquela que Porter e Kramer (2006) definem como uma nova maneira de olhar para a relação entre a sociedade e os negócios, definindo a responsabilidade social corporativa como uma fon- te significativa de progresso social, à medida que a empresa aplica seus recursos estratégicos, experiência e conhecimentos em atividades que beneficiam a sociedade e, para a empresa, se tornam fonte de vantagem competitiva.

No que diz respeito à participação da cadeia de suprimentos reversa do óleo de cozinha utilizado, a empresa focal não participa diretamente como um ator que se envolva em ações de logística, mas participa como incentivadora da cadeia, mesmo sem participar da cadeia produtiva geradora desse resíduo: a cadeia do óleo de cozinha. A estratégia desse ator é de fomentar outro negócio, por meio de estratégias da logística reversa do óleo de cozinha utilizado.

A literatura pertinente aborda o papel dos atores diretamente envolvidos nos fluxos, diretos ou reversos, de produtos e materiais nas cadeias de suprimentos. Nesse sentido, o papel de uma empresa que não participa de maneira direta nas interações de uma cadeia de suprimentos (reversa, neste caso), mas que teve importância decisiva para que essa cadeia fosse estruturada, remete a novas e mais abrangentes concepções teórico -práticas sobre cadeias de suprimentos.

A Liquigás mantém interações com a Porto Gás que extrapolam o vínculo comercial do gás de cozinha, pois essas duas empresas interagem de maneira paralela a essas questões para a implementação de estratégias de recolhimento do óleo de cozinha utilizado. Essas relações são construídas e mantidas sem mecanismos formais de coordenação, supostamente baseadas na confiança.

\section{Empresa Porto Gás}

Essa empresa é uma revenda de gás de cozinha, que faz parte da rede de revendedores da Liquigás Distribuidora. A Porto Gás aderiu de maneira espontânea, há quatro meses, às ações de recolhimento de óleo de cozinha usado e, segundo os gestores da empresa, já resultou em ganhos no faturamento, que significam um incremento aproximado de $20 \%$ na revenda de gás a consumidores residenciais, sem aumento nos seus custos.

Quanto à forma de divulgação dessa estratégia, a Porto Gás optou por folders, que são distribuídos nas caixas de correio. Além disso, os colaboradores da Porto Gás, no momento da entrega, reforçam essa iniciativa perante as donas de casa, porteiros e zeladores de prédios residenciais. Nesse sentido, na entrevista, um desses colaboradores dizia que "[...] tanto os zeladores de prédios residenciais, como donas de casa, acharam excelente a ideia de poder entregar o óleo de cozinha utilizado no momento da substituição do botijão de gás de cozinha e que percebeu um aumento significativo na venda deste produto após a implementação desta estratégia”. 
Em relação à troca de informações com os outros atores da cadeia, os gestores da Porto Gás afirmam que são realizadas reuniões mensais de avaliação com consultores regionais da $\mathrm{Li}$ quigás. Essas reuniões visam à troca de experiências entre os revendedores que recolhem o óleo de cozinha utilizado. Além disso, os consultores regionais fazem visitas periódicas às revendas, monitorando o desempenho na estratégia de recolhimento do óleo de cozinha utilizado.

No que tange aos aspectos estruturais da cadeia de suprimentos reversa do óleo de cozinha, o papel da Porto Gás é de desencadear o processo para (re)utilização do óleo de cozinha utilizado. Na estruturação - configuração de fluxos, a Porto Gás, ao aderir espontaneamente à estratégia da Liquigás e como segundo elo dessa cadeia, assume relevância como ator estratégico, pois é o elo entre a empresa focal, donas de casa e a Coleto Óleos Vegetais Saturados Ltda, empresa especializada na coleta e transporte do óleo vegetal saturado.

Em termos relacionais, a Porto Gás desenvolve interações diretas com a Liquigás, com as donas de casa (primeiro elo da cadeia) e com a Coleto Óleos Vegetais Saturados Ltda. O fato de interagir de maneira direta com três atores da cadeia e ser o único ator que tem interações intensas com estes faz da Porto Gás um ator-chave na cadeia. Além dessa importância, também são relevantes as formas de relacionamento com esses atores, que não são coordenadas por mecanismos formais, mas são baseadas em parcerias informais entre os atores. Esse aspecto é relevante, pois as relações entre os atores da cadeia são todas orientadas por essa lógica.

\section{Coleto Óleos Vegetais Saturados Ltda.}

A Coleto situa-se no município de Porto Alegre e tem, aproximadamente, 2 mil fornecedores de óleo de cozinha utilizado, atendendo $90 \%$ do Rio Grande do Sul, sendo os principais originadores restaurantes, lancherias, bares, hotéis e hospitais, com um volume médio de 170 a 180 toneladas por mês (COLETO, 2012). Recentemente, a Coleto fez uma parceria com o Sindicato de Habitação (Secovi), para aumentar a coleta em condomínios.

O óleo coletado segue para um depósito, onde é feito um processo de filtragem, quando são retirados resíduos sólidos como restos de alimentos, farinhas, entre outros. Após a filtragem, o óleo passa por um processo de decantação, para retirar a umidade.

O óleo tratado é bombeado para tanques de armazenamento, de onde será destinado para fabricação de novos produtos, e toda a água retirada do óleo e do processo de limpeza dos recipientes (coletores), como também de limpeza dos caminhões, passa pelo tratamento de efluentes antes de retornar ao meio ambiente. Os resíduos sólidos retirados do óleo são segregados e encaminhados para um processo de limpeza e reciclagem, transformando-se em composto orgânico.

$\mathrm{Na}$ cadeia analisada, a Coleto interage do lado de seu suprimento, com a Porto Gás, e é fornecedora do Grupo Faros. Em nenhuma das situações, há contratos formais. No caso do grupo Faros, a Coleto se envolveu há, aproximadamente, quatro anos no recolhimento desse resíduo. 0 relacionamento com a Porto Gás é recente (em torno de quatro meses).

O papel desempenhado pela Coleto na cadeia analisada é de ligação entre outros dois elos - à montante com a Porto Gás e à jusante com o Grupo Faros. Não são ligações ou interações complexas, mas que desempenham a função de dar sequência aos fluxos de produtos ao longo da cadeia. A cooperação que a Coleto tem com esses outros elos é no sentido de convergir estratégias comuns em vista da otimização de desempenho da cadeia.

\section{Grupo Faros}

O Grupo Faros utiliza o óleo de cozinha utilizado na produção de um óleo tratado que é vendido para indústrias de biodiesel (o principal mercado) e para empresas de cosméticos, tintas e materiais de limpeza.

Em Cruzeiro do Sul (RS), o Grupo Faros separa os resíduos sólidos retirados do óleo de cozinha utilizado. Esse resíduo vai para a Indústria de Farinha de Ossos Ltda, que o utiliza no processo de fabricação da farinha para rações animais, e o óleo vai para a Base Indústria e Comércio de óleos e Proteínas Ltda. As duas empresas são do Grupo Faros.

Antes de recolher o óleo de cozinha utilizado, a Coleto já trabalhava com recolhimento de resíduos animais para a Indústria de Farinha de Ossos Ltda. Quando o Grupo Faros adquiriu uma empresa que tratava o óleo de cozinha utilizado, foi estabelecida essa nova parceria entre as duas empresas - Grupo Faros e Coleto. Segundo o gestor do Grupo Faros, é intenção dessas duas empresas formalizar um contrato sobre o fornecimento de óleo de cozinha utilizado.

O Grupo Faros mantém interações com a Coleto à montante e à jusante com indústrias de biodiesel, indústrias de tintas, indústrias de materiais de limpeza, indústrias de cosméticos e com grandes distribuidoras de rações animais. O fornecimento a essas empresas não é sistemático e também não há qualquer tipo de contrato formal a respeito dessas relações. As interações, tanto à montante quanto à jusante, são no sentido de cooperar mutuamente e visando ao alinhamento de estratégias afins. Dessa forma, supõe-se que as relações do Grupo Faros e a Coleto sejam baseadas na confiança, porque essas empresas trabalham em parceria há um longo período, sem contratos formais. 


\section{Desenho da cadeia de suprimentos reversa do óleo de cozinha utilizado e implicações para a prática da administração}

Neste estudo, entende-se por cadeia de suprimentos reversa uma cadeia em que o produto, após seu uso ou o final de seu ciclo de vida útil, não retorne à mesma cadeia que the tenha dado origem. Justifica-se essa escolha em virtude de que a análise dessa cadeia evidencia que se estrutura uma cadeia totalmente diferente da original. Se fosse optar por inserir fluxos reversos na cadeia original, estar-se-ia somente a alongando ou trabalhando na lógica da cadeia de circuito fechado - closed-loop chain (GUIDE JUNIOR, HARRISON, VAN WASSENHOVE, 2003).
Essa última difere da primeira em virtude de que a cadeia é ciclo fechado, sendo que o produto, após o final de sua vida útil, retorna à mesma cadeia, enquanto na primeira o produto tem destinos diversos daqueles da cadeia original.

A cadeia de suprimentos reversa do óleo de cozinha utilizado pode apresentar amplitude significativa, dependendo do tipo de aplicação a que se destine esse produto. No caso da cadeia analisada, as aplicações são diversas: rações animais; indústrias de cosméticos; indústrias de materiais de limpeza; indústrias de tintas; indústria de biodiesel.

Na Figura 1, apresenta-se a cadeia de suprimentos reversa do óleo de cozinha utilizado, com destaque para as etapas que são o foco da análise neste estudo.

\section{Figura 1. Cadeia de suprimentos reversa do óleo de cozinha utilizado}

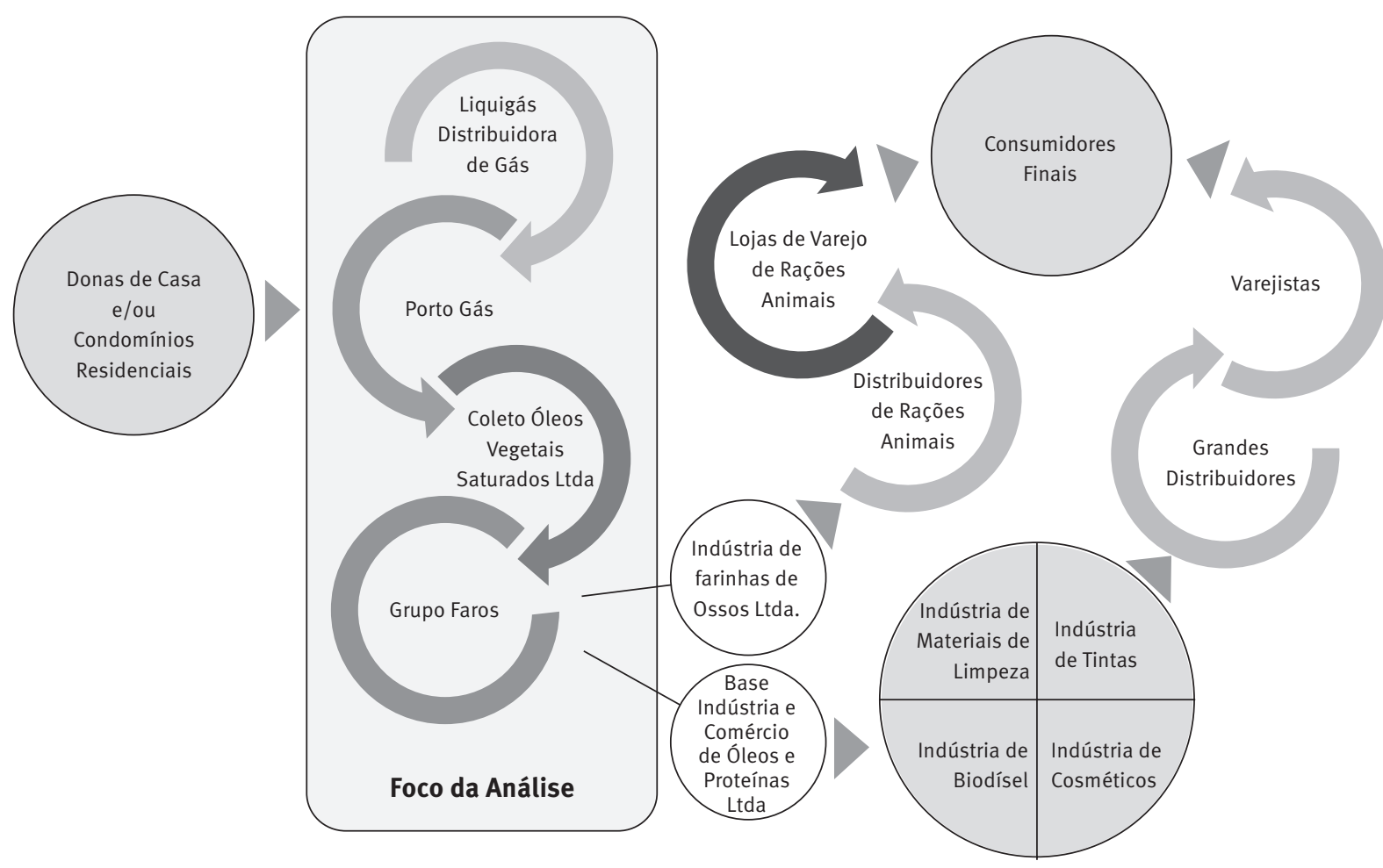

A análise da Figura 1 permite inferir que a Liquigás faz parte da cadeia de maneira direta. Essa empresa, no entanto, consta como um ator da cadeia, não como um elo - elemento de ligação entre dois ou mais nós, como um agente que, indiretamente, atua na condição de elemento propulsor de uma estratégia à qual outro ator adere (de maneira espontânea). Em relação aos outros atores: Porto Gás, Coleto e Grupo Faros, estes, sim, desempenham papéis de conexão entre diferentes elos da cadeia, promovendo o fluxo do produto.

Como implicações para a prática em administração e em termos de avanços no conhecimento, com base nas evidências do estudo, pode-se considerar estratégico:

- antecipar-se às exigências de marcos regulatórios (AGRAWAL, 2012), que tendem a ser mais críticos (a exemplo da Diretiva n. 293/2005, da União Europeia, da Lei n. 9.974, de 2000, e da Lei n. 12.305, no Brasil); 
- buscar parceiros que se alinhem às estratégias da organização em termos de práticas ambientais (WACKER, VIARO, WOLF, 1999);

- promover o envolvimento de múltiplos atores (GUNASEKARAN e NGAI, 2004; VAN VASSENHOVE, 2006) e fomentar o fluxo de informações (GUNASEKARAN e NGAI, 2004);

- preparar-se para lidar com incertezas (WALSH, 2005) e uma ampla gama de possíveis tendências futuras;

- buscar trocas de informações com atores de outras cadeias reversas (e de diferentes produtos) (TERPEND e outros, 2008; RUBIO e outros, 2009).;

- preparar-se constantemente para mudar à luz de estratégias emergentes (TIBBEN-LEMBKE, 2002) e, eventualmente, inusitadas.

Além disto, RSCs podem constituir-se fontes de informações estratégicas, podendo ser empregadas para melhorar o design de produtos, processos e operações. E, como conse- quência, a RSC pode gerar vantagem competitiva às organizações, por meio da otimização de cadeias de suprimentos originais e captura de valor de bens e produtos (BLACKBURN e outros, 2004) que seriam descartados.

\section{CONSIDERAÇÕES FINAIS}

O objetivo deste estudo foi analisar como se estrutura e é coordenada uma cadeia de suprimentos reversa de óleo de cozinha utilizado. Considera-se oportuno pontuar aspectos relevantes que emergiram na realização do estudo.

Inicialmente, aponta-se a forma de coordenação da cadeia analisada, que se baseia na parceria informal entre os atores que interagem ao longo dela. Em nenhuma das relações, há contratos formais ou outro mecanismo qualquer para coordenar a cadeia. 0 Quadro 2 apresenta as principais características da cadeia do óleo de cozinha utilizado.

\section{Quadro 2 - Caracterização da cadeia}

\begin{tabular}{l|l|l}
\hline Empresa & Interações/Relações & Papel na estrutura da cadeia e benefícios alcançados \\
\hline Liquigás Distribuidora de Gás & Empresa Focal & $\begin{array}{l}\text { Concebeu e desenvolveu a ideia } \\
\text { Delimita e incentiva a cadeia } \\
\text { Não participa da cadeia original produtora do óleo } \\
\text { Benefício: responsabilidade social corporativa }\end{array}$ \\
\hline Porto Gás & $\begin{array}{l}\text { Ligação entre 3 elos: } \\
\text { Donas de casa e/ou condomínios; } \\
\text { Liquigás e Coleto }\end{array}$ & $\begin{array}{l}\text { Apoio logístico na coleta de óleo } \\
\text { Sem mecanismos formais de coordenação na coleta de óleo } \\
\text { Benefícios: econômico e financeiro }\end{array}$ \\
\hline Coleto Óleos Vegetais & $\begin{array}{l}\text { Ligação entre 2 elos: } \\
\text { Porto Gás e Grupo Faros }\end{array}$ & $\begin{array}{l}\text { Coleta e transporte de óleo } \\
\text { Sem mecanismos formais de coordenação } \\
\text { Benefícios: econômico e financeiro }\end{array}$ \\
\hline Grupo Faros & $\begin{array}{l}\text { Outros atores para além da cadeia } \\
\text { estudada, como distribuidores, } \\
\text { outras indústrias, consumidores } \\
\text { finais }\end{array}$ & $\begin{array}{l}\text { Transformação do óleo em novos produtos } \\
\text { Sem mecanismos formais de coordenação } \\
\text { Benefício: matéria-prima para novos produtos }\end{array}$ \\
\hline
\end{tabular}

Especificamente no que tange à cadeia estudada, identificouse que:

- há recaptura de valor, por meio da recolocação do resíduo nos processos produtivos;

- a cadeia não é estruturada com base em sua cadeia original, mas induzida por uma empresa que trabalha com outro produto e utiliza a capilaridade de serviços de seus distribuidores para o recolhimento do óleo de cozinha utilizado;

- há o compartilhamento de riscos, sobretudo no que diz respeito à necessidade de desenvolver estratégias para se adequar a eventuais contingências que possam emergir de quadros regulatórios do governo ou por conta de exigências do consumidor;

- não há custos com mecanismos formais de coordenação;

- não há uma empresa ou ator institucional que coordene a cadeia, assim como acontece em outras cadeias, a exemplo das grandes redes varejistas, mas apenas uma empresa que induz o processo;

- as informações ao longo da cadeia são vagas e dispersas, não se verificando compartilhamento e alinhamen- 
to delas, o que pode incorrer na possibilidade de um ator apresentar comportamento oportunista.

Considera-se, ainda, que as inferências deste estudo e outras experiências de logística reversa sugerem que se esteja consolidando mais uma fase da logística, a quinta fase: RSC, a partir das quatro fases propostas por Novaes (2007). Essa evidência, também, se considera como uma das principais contribuições que este estudo oferece. Neste sentido, se procura caracterizar essa quinta fase, considerando-se que a RSC:

- procura (re)colocar nos ciclos produtivos produtos e materiais após o final de seu ciclo de vida útil;

- visa à (re)captura de valor de produtos e materiais que seriam descartados após o final de seu ciclo de vida útil;

- apresenta trocas entre os elos que se dão no sentido contrário ao fluxo normal de materiais e produtos das cadeias originais e, nem sempre, esses produtos e materiais retornam a essas cadeias, podendo ser estruturadas outras cadeias (como é o caso da cadeia analisada neste estudo);

- contribui significativamente para a melhoria das condições do meio ambiente, pela crescente consciência ambiental dos consumidores; e

- possibilita o estabelecimento de diferenciais competitivos, por meio de significativas diferenciações em serviços.

Para ser estruturada uma cadeia de suprimentos reversa, faz-se necessário o envolvimento de inúmeros atores, que precisam ser preparados para essa finalidade, pois a lógica prevalecente é a da não utilização dos produtos ao final do seu ciclo de vida útil. Nesse sentido, considera-se que o fator humano seja de vital importância, conforme sugerem Sarkis, Gonzalez-Torre e Adenso-Diaz (2010), pois é da consciência de cada sujeito que podem brotar e ser implementadas iniciativas, talvez modestas inicialmente, mas que podem se transformar em ações significativas.

Ao final do estudo, pode-se, também, questionar: Por que a indústria de óleo de cozinha, conhecendo o potencial poluidor desse produto, não empreende ações em vista de recolocar o produto nos ciclos produtivos após o final de seu ciclo de vida útil?

Como limitação do estudo, considera-se que o fato de analisar somente alguns elos da cadeia possa induzir a algum tipo de viés, especialmente no que diz respeito às relações entre alguns atores da cadeia, com evidências de que sejam baseadas na mútua confiança.

Para novos estudos, sugere-se a análise comparativa entre diferentes cadeias de óleo de cozinha utilizado. Recomen- dam-se, também, estudos que abranjam a amplitude total da cadeia, desde consumidores residenciais de óleo de cozinha até o consumidor do produto final: biodiesel, cosméticos, tintas etc.

\section{Nota da Redação}

Este artigo foi apresentado no VI Encontro Nacional de Pesquisadores em Gestão Social (ENAPEGS), realizado em 2012, organizado pelos professores Luciano Prates Junqueira, Sylmara Lopes F. Gonçalves-Dias e Patrícia Mendonça.

\section{REFERÊNCIAS}

AGRAWAL, A. Turn your reverse supply chain into a profit center. Supply Chain Quarterly, v.1, n. 1, p. 1-6, 2012.

BARNEY, J; HANSEN, M. H. Trustworthiness as a source of competitive advantage. Strategic Management Journal, v. 15, Issue Suplement 1, p. 175-190, 1994.

BLACKBURN, J. D; GUIDE JÚNIOR, V. D. R; SOUZA, G. C; VAN WASSENHOVE, L. N. Reverse supply chains for commercial returns. California Management Review, v. 46, n. 2, p. 6-23, 2004.

BOWERSOX, D. J; CLOSS, D. J; HELFERICH, O. K. Logistical management: a systems integration of physical distribution, manufacturing, support and materials procurement. 3. ed. New York: Macmillan, 1986.

BRASIL. Casa Civil. Lei no 12.305, de 2 de agosto de 2010. Disponível em: http://www.planalto. gov.br/ccivil_03/_at02007-2010/2010/lei/ l12305.htm. Acesso em 05.05.2013.

CACHON, G. P; KÖK, A. G. Competing manufacturers in a retail supply chain: on contractual form and coordination. Management Science, v. 56, n. 3, p. 571-589, 2010.

CAETANO, M. McDonald's lança projeto de biodiesel a partir do óleo de cozinha. 2010. Disponível em: http://revistagloborural.globo.com/GloboRural/o,6993,EEC1711075-1934,00.html. Acesso em 30.04.2013.

CAMELO, G. R; COELHO, A. S; BORGES, R. M. Alianças estratégicas com fornecedores: um estudo sobre a evolução do relacionamento cliente-fornecedor nos processos logísticos. In: SEMANA DE ENGENHARIA DE PRODUÇÃO SUL-AMERICANA, 10, 2010, Santiago. Anais. Santiago: Usach, 2010.

CERRA, A. L; MAIA, J. L; ALVES FILHO, A. G. Projetos locais de desenvolvimento no contexto das cadeias de suprimentos de montadoras de motores veteranas e entrantes. Gestão e Produção, v. 14, n. 3, p. 505519, 2007.

CHOPRA, S; MEINDL, P. Gerenciamento da cadeia de suprimentos: estratégia, planejamento e operação. São Paulo: Prentice Hall, 2003.

CHOPRA, S; MEINDL, P. Supply chain management: strategy, planning and operation. 4. ed. New Jersey: Pearson Education, 2010.

COELHO, T. M; CASTRO, R; GOBBO Jr, J. A. PET containers in Brazil: opportunities and challenges of a logistics model for post-consumer waste recycling. Resources, Conservation and Recycling, v. 55, n. 3, p. 291-299, 2011. 
COLETO ÓlEOS VEGETAIS SATURADOS LTDA. Por que reciclar o óleo de fritura? Disponivel em: http://www.coleto.com.br/?p=meio-ambiente. Acesso em 20.01.2012.

COMPANHIA DE SANEAMENTO BÁSICO DO ESTADO DE SÃO PAULO. Tratamento de água. Disponível em: http://site.sabesp.com.br/site/interna/ Default.aspx?secaold=491. Acesso em 08.03.2012.

FURLANETTO, E. L. Formação das estruturas de coordenação nas cadeias de suprimentos: estudos de caso em cinco empresas gaúchas. 2002. 306 p. Tese de Doutorado em Administração, Escola de Administração da Universidade Federal do Rio Grande do Sul, Porto Alegre, 2002.

GONÇALVES-DIAS, S; TEODÓSIO, A. S. S. Estrutura da cadeia reversa: "caminhos" e "descaminhos" da embalagem PET. Produção, v. 16, n. 3, p. 429-441, 2006.

GUIDE JUNIOR, V. D. R; HARRISSON, T. P; VAN WASSENHOVE, L. N. The challenge of closed-loop supply chains. Interfaces, v. 33, n. 6, p. 3-6, 2003.

GUIDE JUNIOR, V. D. R; VAN WASSENHOVE, L. N. The reverse supply chain. Harvard Business Review, v. 80, n. 2, p. 25-26, 2002.

GUNASEKARAN, A; NGAI, E. W. T. Information systems in supply chain integration and management. European Journal of Operational Research, v. 159, n. 2, 1, p. 269-295, 2004.

HANDFIELD, R. B; BECHTEL, C. The role of trust and relationship structure in improving supply chain responsiveness. Industrial Marketing Management, v. 31, n. 4, p. 367-382, 2002.

HP BRASIL - Hewlet Packard do Brasil. Participe do programa Planet Partners da HP. 2013. Disponivel em: http://www.hp.com/latam/br/ reciclar/como-participar.html. Acesso em 30.04.2013.

KANDA, A. A; DESHMUKH, S. G. Supply chain coordination: perspectives, empirical studies and research directions. International Journal of Production Economics, v. 115, n. 2, p. 316-335, 2008.

KRIKKE, H. Recovery strategies and reverse logistics network design. Twente: BETA - Institute for Business Engineering and Technology Application, 1998.

KUMAR, S; MALEGEANT, P. Strategic alliance in a closed-loop supply chain, a case of manufacturer and eco-non-profit organization. Technovation, v. 26, n. 10, p.1127-1135, 2006.

JABOUR, C. J. C. In the eye of the storm: exploring the introduction of environmental issues in the production function in Brazilian companies. International Journal of Production Research, v. 48, n. 21, p. 6315-6339, 2010.

JABOUR, A. B. L. S; JABOUR, C. J. C. Evolução da gestão ambiental e a adoção de práticas de green supply chain management no setor eletroeletrônico brasileiro. In: ENCONTRO DA ASSOCIAÇÃO NACIONAL DE PÓS-GRADUAÇÃO E PESQUISA EM ADMINISTRAÇÃO, 36, 2012, Rio de Janeiro Anais. Rio de Janeiro, ANPAD, 2012.

JORNAL LIQUIGÁS. Revendas apostam em conscientização. Porto Alegre, 2009. Disponível em: https://www.liquigas.com.br/wps/wcm/connect/4f523d804e91c1e59826fa0637d31a87/Jornal+Liquigas_edica07. pdf?MOD=AJPERES. Acesso em 22.12.2011.

LACERDA, L. Logística reversa: uma visão sobre os conceitos básicos e as práticas operacionais. Rio de Janeiro, 2002. Disponível em: http://www.coppead.ufrj.br/pesquisa/cel/new/fr-rev.htm. Acesso em 10.01.2012.

LA FUENTE, M. V; ROS, L; CARDÓS, M. Integrating forward and reverse supply chains: application to a metal-mechanic company. International Journal of Production Economics, v. 111, n. 2, p. 782-792, 2008.
LAMBERT, D. M; COOPER, M. C; PAGH, J. D. Supply chain management: implementation issues and research opportunities. International Journal of Logistics Management, v. 9, n. 2, p. 1-20, 1998.

LAMMING, R. Beyond partnership: strategies for innovation and lean supply. Hemel Hempstead: Prentice Hall, 1993.

LARSON, P; POIST, R; HALLDÓRSSON, A. Perspectives on logistics vs. SCM: a survey of SCM professionals. Journal of Business Logistics, v. 28, n. 1, p. $1-25,2007$

LEITE, P. R. Logística reversa: meio ambiente e competitividade. São Paulo: Prentice Hall, 2003.

LEITE, P. R. Direcionadores ("drivers") estratégicos em programas de logística reversa no Brasil. In: SIMPÓSIO DE ADMINISTRAÇÃO DA PRODUÇÃO, LOGÍSTICA E OPERAÇÕES INTERNACIONAIS, 9, 2006, São Paulo. Anais. São Paulo: FGV-EAESP, 2006.

MALHOTRA, N. K. Pesquisa de marketing: uma orientação prática. 4. ed. Porto Alegre: Bookman, 2006.

MARTINS, R; SOUZA, O. V. Análise do alinhamento de práticas colaborativas entre camadas: estudo comparativo de casos nas cadeias automobilísticas de São Paulo e de Minas Gerais. Revista de Administração da UNIMEP, v. 8, n. 3, p. 207-238, 2010.

NOVAES, A. G. Logística e gerenciamento da cadeia de distribuição. 2. ed. Rio de Janeiro: Campus, 2007.

PORTER, M. E; KRAMER, M. R. Strategy and society: the link bettwen competitive advantage and corporate social responsibility. Harvard Business Review, v. 84, n. 12, p. 78-92, 2006.

PRAHINSKI, C; KOCABASOGLU, C. Empirical research opportunities in reverse supply chains. Omega, v. 34, n. 6, p. 519-532, 2006.

PROGRAMA DE GESTÃO AMBIENTAL - PGA. Sabão feito com óleo de cozinha: uma forma de diminuir o efeito estufa e a contaminação das águas. 2012. Disponível em: http://pga.pgr.mpf.gov.br/praticas-sustentaveis/sabao. Acesso em 06.03.2012.

REIS, M. F.P; ELLWANGER, R. M; FLECK, E. Destinação de óleos de frituras. In: CONGRESSO BRASILEIRO DE ENGENHARIA SANITÁRIA E AMBIENTAL, 24, 2007, Belo Horizonte. Anais. Belo Horizonte: ABES, 2007.

REVLOG - The European Working Gorup on Reverse Logistics. Why reverse logistics? Disponivel em: http://www.fbk.eur.nl/OZ/REVLOG/Introduction.htm. Acesso em 25.01.2012.

RODRIGUES, D. M; SELLITTO, M. A. Práticas logísticas colaborativas: o caso de uma cadeia de suprimentos da indústria automobilística. São Paulo, 2007. Disponivel em: http://www. revistasusp.sibi.usp.br/pdf/ rausp/v43n1/v43n1a8.pdf. Acesso em 09.01.2012.

RUBIO, S; MIRANDA, F. J; CHAMORRO, A; VALERO, V. Implementing a reverse logistics system: a case study. International Journal Procurement Management, v. 2, n. 4, p. 346-357, 2009.

SANTOS, R. S. Gerenciamento de resíduos: coleta de óleo de cozinha. 2009. 52 p. Trabalho de Conclusão de Curso em Tecnologia em Logística, Faculdade de Tecnologia da Zona Leste, São Paulo, 2009.

SARKIS, J; GONZALEZ-TORRE, P; ADENSO-DIAZ, B. Stakeholder pressure and the adoption of environmental practices: the mediating effect of training. Journal of Operations Management, v. 28, n. 2, p. 163-176, 2010.

SELLITTO, M. A; MENDES, L. W. Avaliação comparativa do desempenho de três cadeias de suprimentos em manufatura. Produção, v. 16, n. 3, p. 552-568, 2006.

SEVERINO, A. J. Metodologia do trabalho científico. 22. ed. São Paulo: Cortez, 2002. 
SHULTMANN, F; ZUMKELLER, M; RENTZ, O. Modeling reverse logistic tasks within closed-loop supply chains: an example from the automotive industry. European Journal of Operational Research, v. 171, n. 3, p. 1033-1050, 2006.

SILVA, T. N; PEDROZO, E. A; ESTIVALETE, V. F. B; BEGNIS, H. S. M; MARASCHIM, A. F; PASQUAL, C. A; JERÔNIMO, F. B; SILVEIRA, H. S; JARDIM, P. A. J. M; BARATA, T. S. Relações de cooperação e confiança entre organizações cooperativas promovendo capital social. Administração em Diálogo, v. 6, n. 1, p. 37-45, 2004.

SLACK, N; CHAMBERS, S; JOHNSTON, R. Administração da produção. São Paulo: Atlas, 1997.

SLACK, N; CHAMBERS, S; JOHNSTON, R. Administração da produção. 2. ed. São Paulo: Atlas, 2007.

SOUZA, D. P; MENDONÇA, F. M; NUNES, K. R. A; VALLE, R. Environmental and socioeconomic analysis of producing biodiesel from used cooking oil in Rio de Janeiro: the case of the Copacabana district. Journal of Industrial Ecology, v. 16, n. 4, p. 655-664, 2012.

SRIVASTAVA, S. Green supply-chain management: a state-of-the-art literature review. International Journal of Management Reviews, v. 9, n. 1, p. 53-80, 2007.

TALAMINI, E; PEDROZO, E. A; SILVA, A. L. Gestão da cadeia de suprimentos e a segurança do alimento: uma pesquisa exploratória na cadeia exportadora de carne suína. Gestão \& Produção, v. 12, n. 1, p. 107-120, 2005.
TERPEND, R; TYLER, B. B; KRAUSE, D. R; HANDFIELD, R. B. Buyer-supplier relationships: derived value over two decades. Journal of Supply Chain Management, v. 44, n. 2, p. 28-55, 2008.

TIBBEN-LEMBKE, R. S. Life after death: reverse logistics and the product life cycle. International Journal of Physical Distribution \& Logistics Management, v. 32, n. 3, p. 223-244, 2002.

VAN WASSENHOVE, L. N. Humanitarian aid logistics: supply chain management in high gear. Journal of the Operational Research Society, v. 57, n. 5, p. 475-489, 2006.

WACKER, C; VIARO, A; WOLF, M. Partnerships for urban environmental management: the roles of urban authorities, researchers and civil society. Environment \& Urbanization, v. 11, n. 2, p. 113-125, 1999.

WALSH, P. R. Dealing with the uncertainties of environmental change by adding scenario planning to the strategy reformulation equation. Management Decision, v. 43, n. 1, p.113-122, 2005.

WILKE, R. Logística reversa no recolhimento de embalagens vazias de agrotóxicos. 2009. 124 p. Trabalho de Conclusão de Curso em Administração, Escola de Administração da Universidade Federal do Rio Grande do Sul, Porto Alegre, 2009.

WILLIAMSON, O. The mechanisms of governance. Oxford: Oxford University, 1996. 